\title{
Other ways of financing your company
}

\author{
Jörn Aldag, Mark Kessel, Adrian Ibrahim, Ray Hill \& Paul McCubbin \\ The public markets aren't what they used to be and venture capitalists are seeking investments with shorter timelines. \\ But the good news is several new sources of financing are becoming available.
}

lthough levels of financing going into the Abiotech sector overall may be increasing, the number of companies receiving seed investment is down. Almost half of funding from venture capitalists (VCs) goes to companies with drug candidates in the clinic, and angel funding continues to retreat. All of which means it's getting harder for young companies to get up and running. At BIO-Europe in Hamburg, Germany, on November 11 a panel of experts gathered to discuss the financing and partnering landscape, with an eye to the future. The roundtable has been edited to reflect the main themes of that discussion.

With VCs moving away from early-stage biotech, what alternative methods of funding are available?

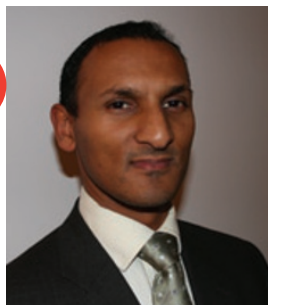

Adrian Ibrahim (AI): At Cancer Research Technology (CRT), we have a discovery fund that is accessed through a peer-review committee, and it provides funds of up to

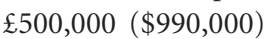

Adrian Ibrahim is the senior business manager at Cancer Research Technology. a time over two-year periods. In terms of research activities, the funds can be used

Jörn Aldag is at Evotec, Schnackenburgallee 114, 22525 Hamburg, Germany. Mark Kessel is at Symphony Capital, 875 Third Avenue, 18th Floor, New York, New York 10022, USA. Paul McCubbin is at BTG, 10 Fleet Place, Limeburner Lane, London, EC4M 7SB, UK. Adrian Ibrahim is at Cancer Research Technology, Sardinia House, Sardinia Street, London, WC2A 3NL, UK. Ray Hill is at Merck/Merck Sharp \& Dohme, Hertford Rd., Hoddesdon, Herts, EN11 9BU, UK.

for anything from target validation to lead optimization studies-we recognize this as a particularly high-risk phase that industry and investors are keen to see overcome before getting involved. We're quite happy to review proposals from anyone on that basis. CRT also has a focused development laboratory — we recognize that progressing technologies is a combination of funding, facilities and expertise.

We've also set up a new program, together with Cancer Research UK's Drug Development Office, called Clinical Development Partnerships. And here we're proactively going out and speaking to companies who have shelved products-shelved because they have another candidate, shelved because they can't raise the finances or shelved because the product has an oncology purpose, but they're developing another one. And we're taking on those compounds with plans to develop them through the end of phase 1 at least and maybe a phase 2 a setting. The Drug Development Office has advanced more than 100 new agents into first-in-human studies and is therefore a partner of outstanding experience in early clinical cancer drug development.

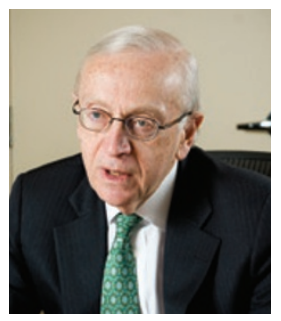

Mark Kessel is managing director at Symphony Capital.

Fibrosis Foundation [Bethesda, Maryland] has been very active in funding large amounts of money into its therapeutic areas.

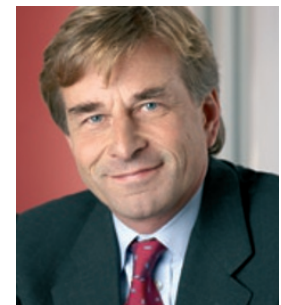

Jörn Aldag is president and CEO of Evotec.
Jörn Aldag (JA): Yes, I'd agree that foundations are investing more and more into virtual organizations and supporting companies long term. At Evotec, we have the Huntington's Disease Foundation as one of our partners. The other angle in Europe is clearly that we see philanthropic families actually moving into the space of financing biotech companies; there are two famous names in Germany: the Hopp family and two brothers Strüngmann. Strüngmann owned Hexal [Holzkirchen, Germany] and sold it to Novartis [Basel] and realized over €6 (\$8.8) billion from that disposal. They're now reinvesting in biotech and they have a very-long term horizon. And, I think, German biotech would have a severe funding issue today if we didn't have those two families I mentionedHopp and Strüngman —investing into earlierstage biotech research.

MK: One other way in which new ideas are being funded is the formation of incubator companies by big pharma; Pfizer [New York], AstraZeneca [London], Biogen Idec [Cambridge, Massachusetts] have all done so. Another form of capital that's been increasing in favor is reverse mergers. There also is venture debt financing. The benefits of that form of financing for companies, obviously, decreases the cost of capital compared with more traditional bank loans. It extends your runway to get greater value inflection points down the road, and it's less dilutive, obviously, than equity.

A little bit of an offshoot on this is some private equity funds that have gotten into what I'll call structured product debt financing-a 
very tailored type of investment. They commit a certain amount of capital, and some of it is put in up front to assist in the financing of specific compounds. And then they loan amounts, either interest bearing or interest free, and they're drawn down at subsequent dates when certain development milestones are met. They generally are predetermined time periods-I think, the longest has been about three years.

Although it may not be applicable to many startups, for those companies that have either revenues from their own internally generated sales or from royalties derived from products that they have out-licensed, royalty financings have become fairly ubiquitous. Another form of financing that is becoming increasingly common is contract research organization [CRO]-linked financings. In the US, one of the larger firms that does this is NovaQuest [Research Triangle Park, North Carolina]. It receives royalties on future product sales and ownership position in the companies, and it makes capital contributions and provides CRO development services and expertise to those companies that need it.

Then we have committed equity-financing facilities. These are designed to really provide a form of equity capital at the choosing of the biotech companies. The way it works is the firm agrees that it will purchase up to a certain amount of equity from the company over a period of time, at a discount to the market at the time that the sales of the equity takes place.

JA: Another funding source in the US is Bill Gates, who has invested substantially into life sciences and is almost taking over the role of VCs today.

MK: But VCs are still going to be important. I think the alternative forms of financing are very small in terms of satisfying the needs of the biotech industry, and I don't think they're going to grow very dramatically, compared to where the main source of funding is coming from. It's a real problem.

And on top of that, the venture capital players are seeing that initial public offerings are really not an exit, and that's why VCs are migrating to later stage. First, to take the company public you need later-stage compounds. And, second, even when a company goes public the VCs can't get out until maybe two years after the company is public. And that's why VCs are increasingly looking for M\&A exits as a way to get out. If you deal with a pharma company and it has an option on your lead compounds, then it's hard to sell the company to anybody other than that firm. But if you do a deal with one of these alternative forms of financing you can still sell it to another company.

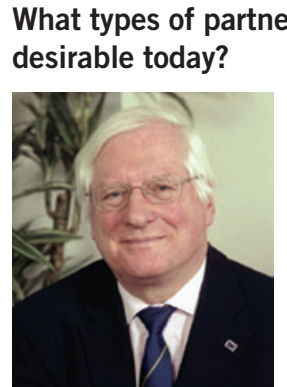

Raymond Hill is executive director and head of licensing and external research at

Europe Merck Sharp \& Dohme.

it, it means that even with abor ple in research and development for Merck, we can still only do about $1 \%$ of the research that we need to know about. For context, last year we looked at around 5,000 potential opportunities and ended up doing 53 deals across the board-partnerships, acquisitions, licensings.

But I don't think that there's a best way to do partnerships between small companies and large companies. I don't think there's any best practice that I could point to and say, Well, this is the way you must do it.

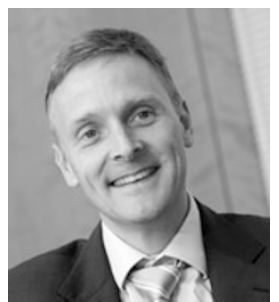

Paul McCubbin is head of business development at BTG International. for people who can work with us not just on a one-off basis, but provide a basis for partnership over time.

So we're probably a lot choosier than we were a few years ago. We're doing fewer deals, but we recognize that that involves a greater level of investment per asset, and also a requirement to pay up front. We see ourselves occupying the space where traditionally Series B investors occupy.

I think there are a number of companies now who are looking to develop their portfolios further into the clinic and trying to capture more value from it and, like ourselves, don't have the in-house research and discovery components, so they're looking to replenish that pipeline through in-licensing.
JA: We're hearing from a few large pharma companies that they're looking for more biotech alliances but have fewer partners to work with. Which essentially means pharma will focus more on longer-term relationships with certain companies, rather than doing opportunistic deals around individual assets. Pharma now is actually looking at partnering with biotechs that can play a more significant longterm role. I agree that pharma's contribution to funding biotech will be significantly larger, in terms of overall deal value, than what the foundations or private investments can ever accomplish.

RH: We're much more likely these days to get into a true 50/50 collaboration with a biotech than to do a simple licensing agreement. Let me use our agreement with NicOx [Sophia Antipolis, France] as a practical example; it's been running for about four-and-a-half years. We've gone from a discovery-stage partnership to taking the first compound into phase 1 firstin-man trials. And NicOx is a company with about 100 employees; we're a company with about 60,000 employees, yet we believe this is a genuine 50/50 partnership. NicOx has retained some commercial rights for France and other parts of Europe.

And we set up the project both in the US and in France, so it's running in two places. For us, face-to-face contact is absolutely vital. And so the teams meet alternately in the US and in France. The meetings help, and we find that we have a very trusting relationship, which, interestingly, has made the project more creative because people don't have any secrets from one another.

MK: As Symphony finances the development of biotech products to phase 2 proof of principle; our biggest competitor is big pharma. But I think today companies prefer to work with us. First of all, we totally align our interest, and we have no back-up compounds. If a compound gets into trouble, like we recently had with one of our collaborations-I can tell you big pharma would've been out of there, whereas we restructured the protocols, etcetera.

But also if you're a publicly traded company and a Merck, a Pfizer, a GlaxoSmithKline [London] bails out on you, watch what happens to your stock price when they abandon a drug or abandon that collaboration. I think you have to pick your partners really carefully and think about the implications, both short term and long term, as to what that collaboration will mean for you.

JA: I think partnering comes down to the people working at biotechs. It's their agility, 
it's their appetite to take risk, it's their unwillingness to be part of a large organization that makes all the difference. They are willing to trade the security of a large organization against the increased freedom and the opportunity to make money faster than you ever can if you're employed in a large organization. I think the most important thing for us is that the pharma partner understands that they need to continue to allow us to live according to that mentality that we have.

MK: It's a matter of trust, I think. When we partner, we are taking the most valuable drugs that companies have; we're not financing the ones that are languishing in the back of big pharma. We're talking about strategic drugs. And you need to have a tremendous amount of trust in the people you're working with because we own the drugs, and so a biotech company should make sure when it turns over products to somebody, it's going to get them back in better shape than when they were inside the company.

\section{Is truly innovative biotech in danger of} becoming extinct as VCs are attracted to other options such as specialty pharma?

JA: A problem for biotechs today is that often investors are in it for a shorter-time horizon than they should be. And this is particularly true today where the VCs have realized that life isn't as easy as it used to be; they need to look at exits and need to look at value creation in the shorter term, which oftentimes leads to making decisions that aren't as mature as you'd normally make. It also leads to venture capital firms investing more downstream in clinical trials.

But that's problematic for biotechs because they begin to focus on things that they're actually no better at than pharmaceutical companies, such as focusing on development rather than the early-stage science, the biology.

PM: VC funds, by and large, have not generated the returns to satisfy their limited partners. It does raise some interesting questions about how well suited realistically the VC model is for doing this early-stage investing.
At the same time, I don't see how this problem can be addressed. Some of the alternative financing schemes that we've mentioned today may have to become part of the answer. But the reality is I'm not quite sure the industry will ever get to a state where the VCs flood back in to the seed stage or Series A [funding rounds].

Increasingly companies will look to fund assets rather than companies. We're seeing it already through players like Symphony at clinical-stage assets where people are better able to evaluate risk now than they were previously, as there's a greater understanding of clinical development.

AI: I think that the benchmarks were wrong when VCs were getting tremendous returns in the late '90s. I don't think it's an entirely bad thing that the VCs have moved away. They moved away for a reason; some of them got burned, and the early-stage biotech and drug development opportunities didn't deliver the value ratios and timelines that they needed. The reality is they probably won't come flooding back. In the UK there are, though, a number of university-focused and funding body-based initiatives that will at least in part replace earlystage VC money. We may also see an increased selection pressure on the formation of companies from opportunities that may actually be better suited to licensing.

\section{What can we expect to see from biotech in the coming years?}

RH: At the moment we're addressing the emerging countries in the European Union. We see countries like the Czech Republic, for example, where Charles University has an enormous history of biomedical research doing very high quality work, as valuable. But there's just no structure in that country to provide the sort of opportunities that are available to academic researchers in, say, the UK or the US. At the moment, we've put an academic scout into our team, specifically tasked to go and look for opportunities where we may have to fund things because there is no other source of funding.

I think that there is such a tremendous pace of science at the moment that I'm very optimistic about the future. I think there are some key problems, like who's going to help us deliver small interfering RNA now that we've bought Sirna Therapeutics [San Francisco]? We know what it will do; we just need to get it there. But, I think there are some really key questions out there that academic groups and other small companies are addressing. And, I think the synergy between big and small companies will continue.

Also, I think we'll see more consolidation. If you look back to the early 2000s, particularly in countries like Germany, there were companies with one employee that apparently were viable by some people's criteria. A lot of that has gone away and there's been some useful consolidation. But I don't think bigger is necessarily better. There are virtual companies with six or seven employees that have done a very good job of taking an idea and developing it.

JA: Here's an analogy: some 30 years ago the car industry was heavily focused on designing nuts and bolts and everything — all the little bits and pieces that went into a car, even the tires. And today when you look at it, their key success factor on a competitive basis is the design and the marketing of cars. All the rest has been given away to other companies who deliver it.

Now if I look at the pharmaceutical industry, it is today still very much focused on the nuts and bolts, where a lot more of this should be given to biotech partners who should be treated on an even footing. And I'm seeing the pharmaceutical industry go away from being disease-oriented and coming in when the disease is already there, to instead looking for prevention at an earlier stage.

And as they're doing it, they're moving toward a model that is far more downstream with regard to marketing. I think they will leave a lot of the science to smaller companies. And, therefore, I do see the six-employee, virtual company being successful, but I also see consolidation. I see a maturing biotech industry, one that can reliably deliver proof of concept and even compounds further downstream to the pharmaceutical industry. That will leave pharma to continue to make its money on marketing drugs. 